\title{
A Novel Active Disturbance Rejection Control with a Super-Twisting Observer for the Rocket Launcher Servo System
}

\author{
Di-Fen Shi $\mathbb{D}^{\mathrm{D}}$, Yuan-Long Hou $\left(\mathbb{D}\right.$, Xiao-Hui Gu ${ }^{D}$, and Run-Min Hou \\ School of Mechanical Engineering, Nanjing University of Science and Technology, Nanjing 210094, China \\ Correspondence should be addressed to Yuan-Long Hou; houyuanlong1964@163.com
}

Received 14 December 2020; Revised 26 April 2021; Accepted 11 June 2021; Published 30 June 2021

Academic Editor: Wahyu Caesarendra

Copyright (c) 2021 Di-Fen Shi et al. This is an open access article distributed under the Creative Commons Attribution License, which permits unrestricted use, distribution, and reproduction in any medium, provided the original work is properly cited.

In this paper, a novel active disturbance rejection control (NADRC) with a super-twisting extended state observer (SESO) is utilized in the rocket launcher servo system. The main arguments in the shipborne rocket launcher system are control accuracy and antidisturbance ability, which are closely related to phase delay and bandwidth. Firstly, we use Taylor's formula approach to compensate the phase delay in traditional tracking differentiator (TD). Secondly, we design the parallel structured SESO to improve the observation bandwidth, so that it can estimate states with desired accuracy in NADRC. Finally, sinusoidal simulation results show Taylor's formula-based TD can suppress noise and compensate phase delays effectively. In comparison with traditional ADRC, the proposed NADRC is shown to have better tracking performance and stronger robustness. Semiphysical experiments are conducted to prove the feasibility of NADRC.

\section{Introduction}

Permanent magnet synchronous motors (PMSMs) have many merits such as large torque density, high efficiency, and fast response. Therefore, PMSMs have received significant attention in engineering research field like electric vehicles (EVs), spacecraft, and pneumatic servo system [1]. PMSMs are also used in the shipborne rocket launcher system with advanced control technology [2-6]. The marine condition features multivariable and intricate disturbances, as well as strong nonlinear effects. Therefore, rapidly changing disturbances become the main vulnerability of the shipborne rocket launcher system. In practical working conditions, strong robustness and adaptivity are demanded for a PMSM controller. Various effective control methods are investigated in [7-12].

The controller in shipborne rocket launcher system needs to solve the nonlinear issue caused by marine conditions and friction. The proportional-integral-derivative (PID) is an effective scheme for the nonlinear problem. As one of the foremost pioneers in the development of the control method, Jingqing Han proposes the active disturbance rejection control (ADRC) [13] to overcome the shortcomings of the PID; hence, it has been developed in recent years [14]. ADRC commonly consists of a tracking differentiator (TD), an extended state observer (ESO), and a nonlinear state error feedback (NLSEF) system. Numerous techniques are proposed to improve antidisturbance and robustness properties $[15,16]$.

TD based on Taylor's formula is clarified and analyzed in [17], aiming at tackling the phase-delay issue from TD. The key role of ESO is to observe total disturbances and transfer the real-time observations to NLSEF. Fractionalorder extended state observer is presented to observe the total disturbance in [18]. However, high switching gain leads to chattering and steady state fluctuation. A supertwisting extended state observer (SESO) emerges with stability in finite time and has better performance compared with conventional extended state observer in the nonlinear system $[19,20]$. Besides, a super-twisting algorithm based higher order sliding mode observer (HOSMO) is devised in [21]. The aforementioned secondorder ESO contains the nondifferential term $k_{2} \operatorname{sign}\left(e_{1}\right)$, which is hard to reach the second-order sliding mode. By using a HOSMO, this term can successfully converge to the desired sliding surface. 
Due to the promising property of strong robustness, the sliding mode control has received significant popularity [22-25]. However, the chattering phenomenon is indisputable coupled with control processing and the convergence is also slow. Nonsingular fast terminal sliding mode control (NFTSMC) is recently reported, which can guarantee convergence to zero in finite time and eliminate chattering phenomenon efficiently [26]. Aiming to reduce tracking error and improve antidisturbance property, an adaptive recursive terminal sliding mode (ARTSM) controller is investigated in [27]. The performance of SMC degrades when dealing with chattering problem; several auxiliary control approaches like adaptive fuzzy PID and adaptive neural network have been embedded in FNTSM [28-31]. ADRC with FNTSMC is developed in [32], which retains the merits of the ADRC of antidisturbance and the FNTSMC with fast convergence speed. Moreover, instead of traditional cascade structure, the parallel structure in position and speed loop is one of the most practical ways to improve dynamic responses [33]. The overall structure of shipborne rocket launcher system is shown in Figure 1, where STM32 microcontroller uses C programming language to simulate the position loop and speed loop control. Control computer is used to send command signal through $\mathrm{C}++$ programming language.

As the previously mentioned control technologies suffer from some limitations, this paper proposes a NADRC system with a parallel structure, mainly seeking to address the following problems:

(1) Taylor's formula-based tracking differentiator (TD) is innovated with Taylor's formula and nonlinear function $\operatorname{fhan}(\cdot)$. The new method can compensate phase delay and acquire desired control command, which solve the phase-delay problem in traditional TD effectively.

(2) Super-twisting algorithm is used to incorporate with ESO, which forms the so-called SESO. It is applied in NADRC to achieve higher tracking accuracy and better robustness. Utilizing super-twisting algorithm and $\tanh \left(\operatorname{Fal}\left(e, k_{3}, c\right)\right)$ function, SESO can estimate disturbance quickly. By raising parameter $k_{3}$ in $\tanh \left(\operatorname{Fal}\left(e, k_{3}, c\right)\right)$, the observation accuracy and bandwidth can be improved.

(3) Fast nonsingular terminal sliding mode control (FNTSMC) in NADRC is used to replace the traditional nonlinear state error feedback controller. The FNTSMC has the ability to reach the target position in short time with the estimated position, speed, and disturbance by SESO.

\section{Modeling of PMSM in the Rocket Launcher Servo System}

2.1. Modeling of PMSM. In this shipborne rocket launcher system, the surface-mounted PMSM is implemented for attitude control. The mathematical model in the $d-q$ coordinate system is given as

$$
\left\{\begin{array}{l}
\dot{i}_{d}=-\frac{R}{L} i_{d}+p \omega i_{q}+\frac{u_{d}}{L}, \\
\dot{i}_{q}=-\frac{R}{L} i_{q}-p \omega i_{d}-\frac{p \psi_{f}}{L}+\frac{u_{q}}{L}, \\
\dot{\omega}=\frac{1}{J}\left(K_{e} i_{q}-T_{L}-B \omega\right),
\end{array}\right.
$$

where $u_{d}, u_{q}$ are the stator voltages; $i_{d}, i_{q}$ are the stator currents; $L_{d}, L_{q}$ are the stator inductance; $\psi_{f}$ is the magnetic flux; $R$ is the stator resistance; $p$ is the pole-pair number of PMSM; $J$ is the inertia moment of the rotor; $B$ is the friction modulus; $\omega$ is the angular velocity of the rotor; $K_{e}$ is the torque constant $\left(T_{e}=(3 / 2) p \psi_{f} i_{q}=K_{e} i_{q}, p\right.$ is the pole-pair number); and $T_{L}$ is the load torque.

Setting disturbance

as $\xi(t)=-\left(T_{L} / J\right)-(B \omega / J)-\left(K_{e} / J\right)\left(i_{q}^{*}-i_{q}\right)$ and substituting $\xi(t)$ into the second equation in (1) derives the following equation:

$$
\left\{\begin{array}{l}
\dot{\omega}=\frac{1}{J}\left(K_{e} i_{q}-T_{L}-B \omega\right) \\
\xi(t)=-\frac{T_{L}}{J}-\frac{B \omega}{J}-\frac{K_{e}}{J}\left(i_{q}^{*}-i_{q}\right) \\
\dot{\omega}=\frac{K_{e}}{J} i_{q}^{*}+\xi(t)
\end{array}\right.
$$

Defining $b=\left(K_{e} / J\right)$ as the coefficient of $i_{q}^{*}$, we obtain

$$
\left\{\begin{array}{l}
\dot{\theta}=\omega \\
\dot{\omega}=b i_{q}^{*}+\xi(t), \\
y=\theta
\end{array}\right.
$$

2.2. Overall Structure of the Rocket Launcher System. The rocket launcher servo system is designed as in Figure 2. The NADRC controller is constructed with a Taylor's formulabased tracking differentiator, a super-twisting extended state observer (SESO), and a fast nonsingular terminal sliding mode control (FNTSMC) system.

\section{SESO-Based NADRC}

High bandwidth is a critical factor to enhance antidisturbance performance in NADRC. A parallel structure between the position loop and speed loop helps to enlarge the bandwidth and modify the frequency bandwidth, as shown in Figure 3, where $\theta^{*}(t)$ is the desired position, $\theta(t)$ is the $t$ position control signal, and $\omega(t)$ is the speed control signal.

3.1. Taylor's Formula-Based Tracking Differentiator. To suppress the chattering of the control input, a tracking differentiator is adopted to achieve smooth tracking. A 


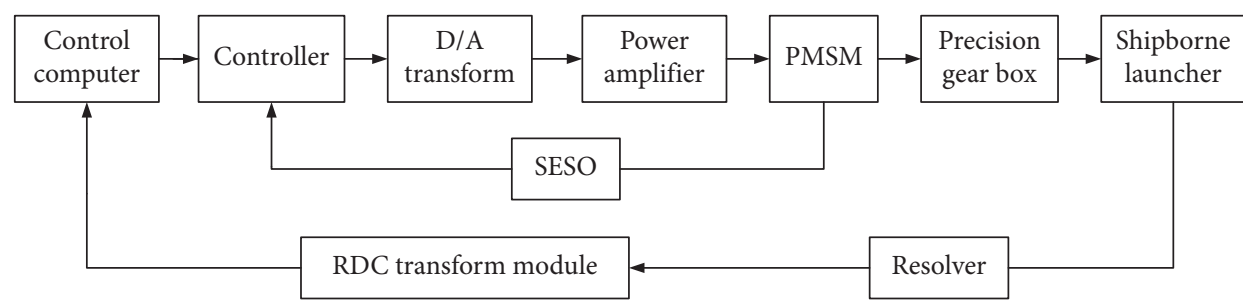

Figure 1: Structure of the rocket launcher servo system.

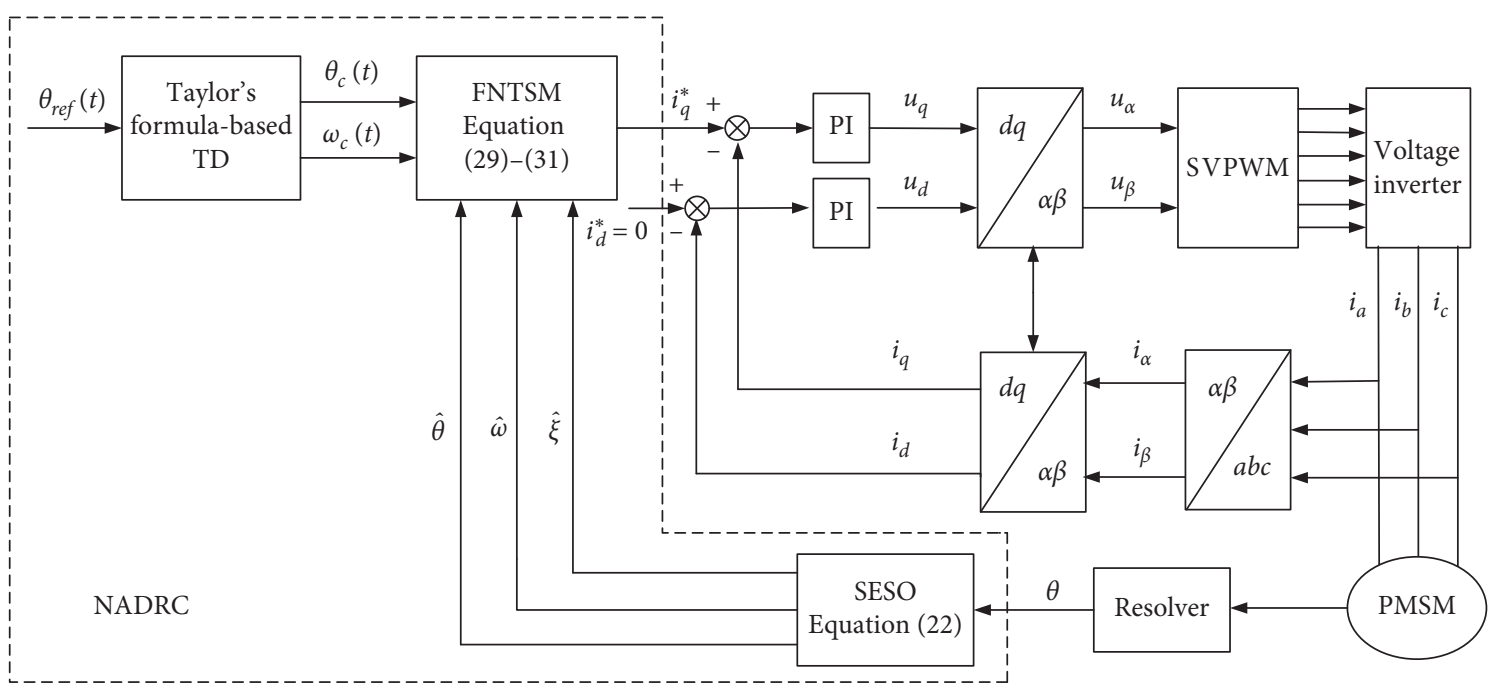

FIgURe 2: Structure of the PMSM drive in the rocket launcher servo system.

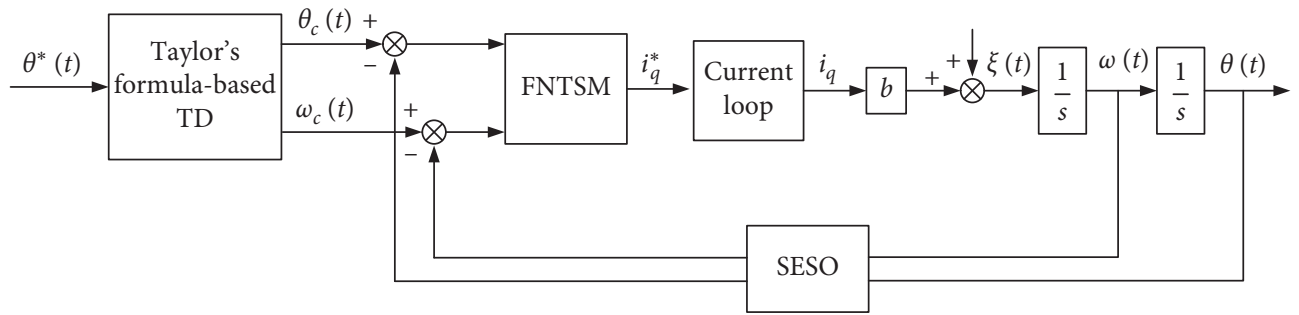

FIgURE 3: Parallel structure in position and speed control loop.

drawback of a standard TD is that it is not able to deal with phase delay. A traditional TD can be described as

$$
\begin{aligned}
\theta(k+1) & =\theta(k)+h \omega(k), \\
\omega(k+1) & =\omega(k)+h f h a n\left(\theta(k), \omega(k), r_{0}, h_{0}\right),
\end{aligned}
$$

where $\theta(t)$ is the adjusted position control signal; $r$ is the speed control factor; $h_{0}$ is the filtering coefficient; and $h$ is the sampling step. Generally, large $h_{0}$ is conducive to restrain noise and high $r$ can raise tracking accuracy. The nonlinear operator fhan (.) in equation (4) is commonly used in ADRC applications, which is given in [13] 


$$
\begin{aligned}
d & =h_{0} r_{0}^{2}, \\
a_{0} & =h_{0} \omega(k), \\
y & =\theta(k)+a_{0}, \\
a_{1} & =\sqrt{d(d+8|y|),} \\
a_{2} & =a_{0}+\operatorname{sign} \frac{\left(a_{1}-d\right)}{2}, \\
s_{y} & =\left(\operatorname{sign}(y+d)-\operatorname{sign} \frac{(y-d)}{2}\right), \\
a & =\left(a_{0}+y-a_{2}\right) s_{y}+a_{2}, \\
s_{a} & =\left(\operatorname{sign}(a+d)-\operatorname{sign} \frac{(a-d)}{2}\right), \\
\text { fhan } & =-r_{0}\left(\frac{a}{d}-\operatorname{sign}(a)\right) s_{a}-r_{0} \operatorname{sign}(a) .
\end{aligned}
$$

The phase delay resulting from TD is compensated by Taylor's formula approach; Taylor's formula is used to compensate phase delay in TD [18], and it can be expressed as

$$
\begin{aligned}
\tilde{g}_{d}\left(k_{n+1}\right)= & g_{d}\left(k_{n}\right)+\frac{g_{d}^{\prime}\left(k_{n}\right)}{1 !}\left(k_{n+1}-k_{n}\right) \\
& +\frac{g_{d}^{\prime \prime}\left(k_{n}\right)}{2 !}\left(k_{n+1}-k_{n}\right)^{2}+\cdots+\frac{g_{d}^{(n)}\left(k_{n}\right)}{n !}\left(k_{n+1}-k_{n}\right)^{n} \\
& +\frac{g_{d}{ }^{(n+1)}(\xi)}{(n+1) !}\left(k_{n+1}-k_{n}\right)^{n+1} .
\end{aligned}
$$

Denoting $\theta^{*}$ as the tracking reference and $\Delta t$ as the time interval, the second-order tracking differentiator is as follows:

$$
\theta^{*}(t)=\theta(t)+\theta \prime(t) \Delta t+\frac{1}{2} \theta \prime \prime(\xi) \Delta t^{2},
$$

where $\theta^{*}(t)$ is the input and $\theta(t+\Delta t)$ is the output.

Theorem 1. Assume $\left\|\theta^{(i+1)}(t)\right\|_{\infty}<\infty, i=0,1$. There exists $a$ positive constant $a$, satisfying

$$
\lim _{\Delta t \rightarrow 0}\left[\theta^{(i)}(t+\Delta t)-\theta^{*(i)}(t)\right]=0, \quad t \in[a .+\infty) .
$$

Proof. Differential of (7) can be written as

$$
\theta^{*(i)}(t)=\theta^{(i)}(t)+\theta^{(i+1)}(t) \Delta t+\frac{1}{2} \theta^{(i+2)}(t) \Delta t^{2} .
$$

Taylor's formula-based expansion of $\theta^{(i)}(t)$ is

$$
\begin{aligned}
\theta^{(i)}(t+\Delta t)= & \theta^{(i)}(t) \Delta t+\theta^{(i+1)}(t) \Delta t \\
& +\frac{1}{2} \theta^{(i+2)}(\xi) \Delta t^{2}, \quad \xi \in(t, t+\Delta t) .
\end{aligned}
$$

The absolute value of equation (10) minus equation (9) is

$$
\left|\theta^{(i)}(t+\Delta t)-\theta^{*(i)}(t)\right| \leq\left|\frac{1}{2} \theta^{(i+2)}(\xi) \Delta t^{2}\right|+\left|\frac{1}{2} \theta^{(i+2)}(t) \Delta t^{2}\right| \text {. }
$$

Replacing $t$ with $s \cdot \Delta t$ and setting $y_{i}(s)=\theta^{*(i+1)}(s \cdot \Delta t)$, the differential of (8) is

$$
\theta^{*(i+1)}(s \cdot \Delta t)=y_{i}(s)+\frac{\mathrm{d}}{\mathrm{d} s} y_{i}(s)+\frac{1}{2} \frac{\mathrm{d}^{2}}{\mathrm{~d} s^{2}} y_{i}(s)
$$

Equation (12) can be rewritten as

$$
\frac{\mathrm{d}}{\mathrm{d} s} Y_{i}(s)=A Y_{i}(s)+\vartheta
$$

where

$$
\begin{aligned}
& Y_{i}(s)=\left[\begin{array}{c}
y_{i}(s) \\
\frac{\mathrm{d}}{\mathrm{d} s} y_{i}(s)
\end{array}\right], \\
& A=\left[\begin{array}{cc}
0 & 1 \\
-2 & -2
\end{array}\right] \text {, } \\
& \vartheta=\left[\begin{array}{c}
0 \\
2 \theta^{*(i+1)}(s \cdot \Delta t)
\end{array}\right] .
\end{aligned}
$$

The solution for equation (13) can be given as

$$
Y_{i}(s)=e^{A s} Y_{i}(0)+\int_{0}^{s} e^{A(s-\tau)} \vartheta(\tau) \mathrm{d} \tau,
$$

where $A$ is Hurwitz, $\sigma \rho>0$ and $\left\|e^{A s}\right\|_{F} \leq \rho e^{-\sigma s}$. Then we have

$$
\begin{aligned}
\left\|Y_{i}(s)\right\|_{2} & \leq\left\|e^{A s} Y_{i}(0)\right\|_{2}+\left\|\int_{0}^{s} e^{A(s-\tau)} \vartheta(\tau)\right\|_{2} \\
& \leq\left\|Y_{i}(0)\right\|_{2} \rho e^{-\sigma s}+\int_{0}^{s}\|\vartheta(\tau)\|_{2} \rho e^{-\sigma(s-\tau)} \mathrm{d} \tau \\
& \leq\left\|Y_{i}(0)\right\|_{2} \rho e^{-\sigma s}+\frac{2 \rho}{\sigma}\left\|\theta^{*(i+1)}(s \cdot \Delta t)\right\|_{\infty}, \\
\left|\frac{1}{2} \theta^{(i+2)}(\xi) \Delta t^{2}\right| & =\frac{1}{2} \Delta t^{2}\left|\frac{\mathrm{d}^{2}}{\mathrm{~d} s^{2}} y_{i}(s)\right|=\frac{1}{2} \Delta t^{2}\left\|Y_{i}(s)\right\|_{2} \\
\leq & \frac{\rho e^{-\sigma s}}{2}\left\|Y_{i}(0)\right\|_{2}+\frac{\rho}{\sigma}\left\|\theta^{*(i+1)}(s \cdot \Delta t)\right\|_{\infty} .
\end{aligned}
$$

Combining $\left|(1 / 2) \theta^{(i+2)}(t) \Delta t^{2}\right| \longrightarrow 0 \quad(\Delta t \longrightarrow 0)$ and (11), equation (8) is proved. Based on the above analysis, Taylor's formula-based TD is given as 


$$
\begin{aligned}
& \theta_{c}(t+\Delta t)=\theta(t)+\theta \prime(t) \Delta t+\frac{1}{2} \theta \prime \prime(\xi) \Delta t^{2}, \\
& \omega_{c}(t+\Delta t)=\omega(t)+\Delta t \cdot f h a n\left(\theta(k), \omega(k), r_{0}, h_{0}\right)+\frac{1}{2} \omega \prime \prime(\xi) \Delta t^{2} .
\end{aligned}
$$

3.2. Super-Twisting Extended State Observer. The aforementioned dynamic model of the system can be rewritten as

$$
\left\{\begin{array}{l}
\dot{\theta}=\omega \\
\dot{\omega}=b i_{q}^{*}+\xi(t) \\
y=\theta
\end{array}\right.
$$

Super-twisting algorithm is applied in SESO, which observes $\theta, \omega$, and $\xi$ in (18), respectively. Fal is a nonsmooth function proposed by the researcher Han [13]. Li et al.'s research shows the nonsmooth control has better anti-interference performance than the smooth control [34]. The Fal function is given by

$$
\mathrm{Fal}= \begin{cases}\frac{e}{\delta^{1-\alpha}}, & |e| \leq \delta \\ |e|^{\alpha} \operatorname{sign}(e), & |e|>\delta\end{cases}
$$

The Fal function is drawn as in Figure 4. We note that when $0<\alpha<1, \delta$ is the threshold of nonsmooth interval. Specifically, if $|e|<\delta$, it is linear which is useful to prevent high-frequency fluctuations caused by high gains in sign function. And if $|e|>\delta$, it is not smooth. The overall consideration of balance between sign function and linear function leads to constraining the ranges of $\alpha$ and $\delta$ within [0 $1]$.

The hyperbolic tangent nonlinear function $\tanh (\operatorname{Fal}(e, \beta, c))$ is much smoother than the Fal function, which can alleviate chattering problem effectively [35].

$$
\tanh (\operatorname{Fal}(e, \beta, c))=\beta \tanh (c e)
$$

where $e$ is the input, and $\beta$ and $c$ are parameters to be adjusted. $\tanh (\operatorname{Fal}(e, \beta, c))$ function is plotted in Figure 4. It can be seen that if $\alpha=0$ and $|e|>\delta$, the output is $-\beta$ or $\beta$. The smaller $c$ results in a smoother transition curve when $e$ is close to 0 .

The speed error is defined as $e=\omega_{c}(t)-\widehat{\omega}(t)$. The observed value is expressed as $\widehat{\theta}, \widehat{\omega}$, and $\widehat{\xi}$. The third-order state extended observer is

$$
\left\{\begin{array}{l}
\dot{\hat{\theta}}=\widehat{\omega}+k_{1}|e|^{2 / 3} \operatorname{sign}(e), \\
\dot{\hat{\omega}}=\widehat{\xi}+b i_{q}^{*}+k_{2}|e|^{1 / 3} \operatorname{sign}(e), \\
\dot{\vec{\xi}}=-\tanh \left(\operatorname{Fal}\left(e, k_{3}, c\right)\right) .
\end{array}\right.
$$

The observer parameters are obtained by setting $k_{1}=$ $1.5 \sqrt{\tau}$ and $k_{2}=1.1 \tau$, where the constant boundary $\tau$ is defined as $|\widehat{\xi}|<\tau$. And $k_{3}$ is time-varying parameter which is determined by $\beta$ and $c$, as shown in Figure 5 .
3.3. Fast Nonsingular Terminal Sliding Mode Control (FNTSM). FNTSM approach is proposed for speed control. The speed error is defined as $e=\omega_{c}(t)-\widehat{\omega}(t)$. Then, the derivative of $e$ is

$$
\begin{aligned}
\dot{e} & =\dot{\omega}_{c}(t)-\dot{\hat{\omega}}(t) \\
& =\dot{\omega}_{c}-\widehat{\xi}-b i_{q}^{*}-k_{2}|e|^{1 / 3} \operatorname{sign}(e) .
\end{aligned}
$$

Nonsingular terminal sliding mode (NTSM) has been proposed for finite-time convergence to zero of the sliding variables.

$$
s=e+\beta \operatorname{sign}(\dot{e})|\dot{e}|^{\sigma},
$$

where $\beta>0$ and $1<\sigma<2$.

NTSM has the property of finite-time convergence to zero of the sliding variables. Setting $s=0$ yields the relation between position and velocity $e=-\beta \operatorname{sign}(\dot{e})|\dot{e}|^{\sigma}$. Note moving from $|e(0)|$ to 0 takes time $T_{n}=\int_{|e(0)|}^{0}(1 / \dot{e}) \mathrm{d} e$. And from (24), we have $\left(1 /|\dot{e}|^{\sigma}\right)=-(\beta \operatorname{sign}(\dot{e} / e))$; thus $\int_{|e(0)|}^{0}$ $(1 / \dot{e}) \mathrm{d} e=\int_{0}^{e(0)}(\beta \operatorname{sign}(\dot{e} / e)) \mathrm{d} e$. Then we have the convergence time:

$$
\begin{aligned}
T_{n} & =\int_{0}^{|e(0)|} \frac{\beta^{1 / \sigma}}{|e|^{1 / \sigma}} \mathrm{de} \\
& =\frac{\beta^{1 / \sigma}|e(0)|^{1-(1 / \sigma)}}{(1-(1 / \sigma))}
\end{aligned}
$$

NTSM overcomes the singularity problem when the sliding states are far away from the equilibrium condition. Nevertheless, the convergence is slow. To improve convergence speed, FNTSM is proposed according to

$$
s=e+\beta \operatorname{sign}(\dot{e})|\dot{e}|^{\sigma}+k_{2}|e|^{1 / 3} \operatorname{sign}(e)
$$

where $\beta>0$ and $1<\sigma<2$.

Similarly, by setting $s=0$, we have $e+k_{2}|e|^{1 / 3} \operatorname{sign}(e)=$ $-\beta \operatorname{sign}(\dot{e})|\dot{e}|^{\sigma}$, which can be $1 /|\dot{e}|^{\sigma}=\beta \operatorname{sign}(\dot{e}) / e+k_{2}|e|^{1 / 3} \operatorname{sign}$ $(e)$. And by $T_{f}=\int_{|e(0)|}^{0}\left(1 /|\dot{e}|^{\sigma}\right) \mathrm{d} e=\int_{0}^{e(0)} \beta \operatorname{sign}(\dot{e}) / e+k_{2}|e|^{1 / 3}$ $\operatorname{sign}(e)$, we can derive the time to achieve the equilibrium condition

$$
T_{f}=\int_{0}^{|e(0)|} \frac{\beta^{1 / \sigma}}{\left(|e|+k_{2}|e|^{1 / 3}\right)^{1 / \sigma}} \mathrm{de} .
$$
that

Note that because $\left(|e|+k_{2}|e|^{1 / 3}\right)^{1 / \sigma}>|e|^{1 / \sigma}$, we can prove

$$
T_{n}=\int_{0}^{|e(0)|} \frac{\beta^{1 / \sigma}}{|e|^{1 / \sigma}} \mathrm{d} e>\int_{0}^{|e(0)|} \frac{\beta^{1 / \sigma}}{\left(|e|+k_{2}|e|^{1 / 3}\right)^{1 / \sigma}} \mathrm{d} e=T_{f}
$$

Therefore, the FNTSM method can achieve the equilibrium point more quickly than the NTSM.

For the speed error $e$, it can reach equilibrium condition $(s=0)$ in finite time if FNTSM manifold is given as equation (26), and the corresponding control law is 


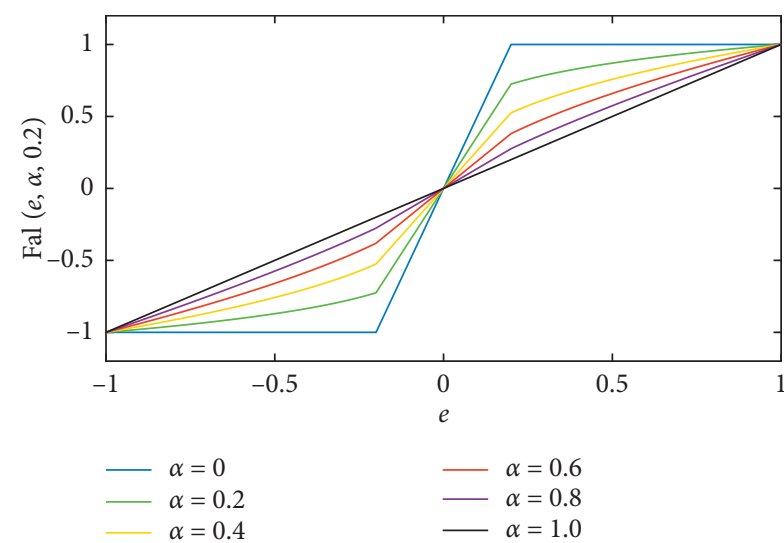

(a)

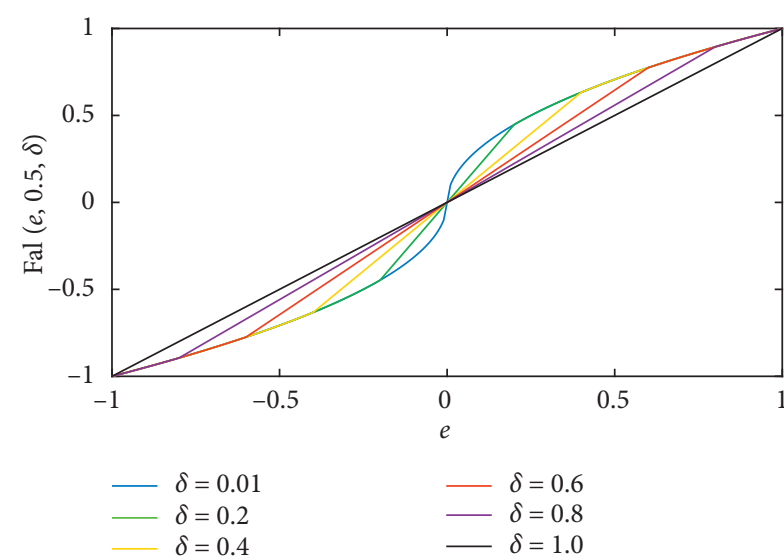

(b)

FIgure 4: Properties of the Fal function with different $\alpha$ and $\delta$ values.

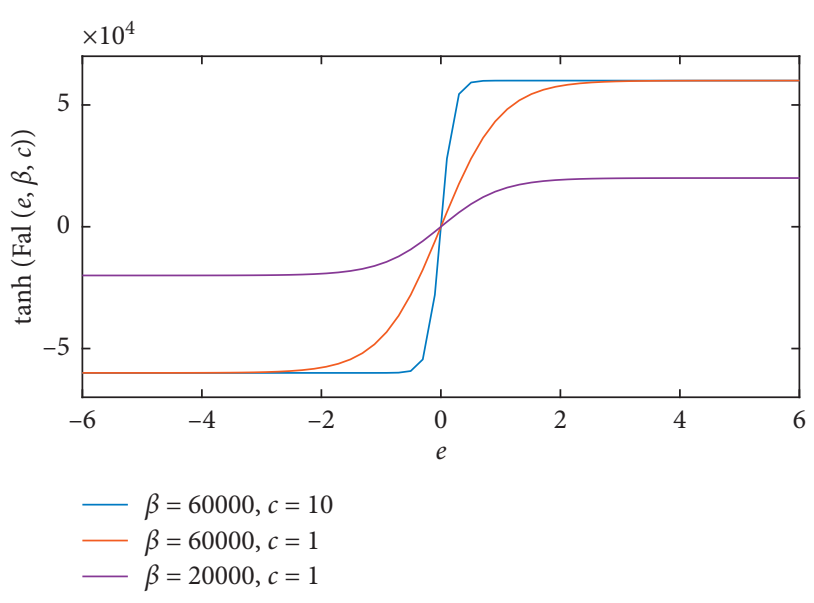

Figure 5: Properties of the $\tanh (\operatorname{Fal}(e, \beta, c))$ function.

$$
\begin{aligned}
& i_{q}^{*}=b^{-1}\left(i_{e q}+i_{b}-\widehat{\xi}\right), \\
& i_{e q}=\dot{\omega}_{c}+\beta \operatorname{sign}(\dot{e})|\dot{e}|^{\sigma}, \\
& i_{b}=\int_{0}^{t} \beta_{0} s+\gamma_{0} s^{q / p} \mathrm{~d} \tau,
\end{aligned}
$$

where $p$ and $q$ are positive odd numbers $(p>q)$, and $\beta_{0}$ and $\gamma_{0}\left(\gamma_{0}>\varsigma\right)$ are positive constants.

According to equations (26) and (29)-(31), we design the following FNTSMC sliding surface:

$$
\begin{aligned}
s= & \dot{e}_{\omega}+\beta \operatorname{sign}(\dot{e})|\dot{e}|^{\sigma}+k_{2}|e|^{1 / 3} \operatorname{sign}(e) \\
= & \dot{\omega}_{c}-b i_{q}^{*}-\widehat{\xi}-k_{2}|e|^{1 / 3} \operatorname{sign}(e)+\beta \operatorname{sign}(\dot{e})|\dot{e}|^{\sigma} \\
& +k_{2}|e|^{1 / 3} \operatorname{sign}(e) .
\end{aligned}
$$

By substituting (29) and (30) into (32), FNTSMC can be derived as follows:

$$
\begin{aligned}
s= & \dot{\omega}_{c}-b\left[b^{-1}\left(i_{e q}+i_{b}-\xi\right)\right]-\widehat{\xi}-k_{2}|e|^{1 / 3} \operatorname{sign}(e) \\
& +\beta \operatorname{sign}(\dot{e})|\dot{e}|^{\sigma}+k_{2}|e|^{1 / 3} \operatorname{sign}(e) \\
= & \dot{\omega}_{c}-\left(\dot{\omega}_{c}+\beta \operatorname{sign}(\dot{e})|\dot{e}|^{\sigma}+i_{b}\right)-\widehat{\xi}+\beta \operatorname{sign}(\dot{e})|\dot{e}|^{\sigma} \\
= & -i_{b}-\widehat{\xi} .
\end{aligned}
$$

Equation (33) is simplified as

$$
s=-i_{b}-\widehat{\xi} .
$$

Then, the derivative of (34) is

$$
\dot{s}=s=-\dot{i_{b}}-\dot{\vec{\xi}}=-\beta_{0} s-\gamma_{0} s^{q / p}+\tanh \left(\operatorname{Fal}\left(e, k_{3}, c\right)\right) \text {. }
$$

In order to verify the feasibility of the proposed method and analyze whether speed error can converge to zero in finite time, we set Lyapunov function as

$$
V=\frac{1}{2} s^{2}
$$

It can be calculated as follows:

$$
\begin{aligned}
\dot{V} & =s \dot{s}=s\left(-\beta_{0} s-\gamma_{0} s^{q / p}+\tanh \left(\operatorname{Fal}\left(e, k_{3}, c\right)\right)\right) \\
& =-\beta_{0}\|s\|^{2}-\gamma_{0}\|s\|^{(q+p) / p}+\tanh \left(\operatorname{Fal}\left(e, k_{3}, c\right)\right) s \\
& \leq-\beta_{0}\|s\|^{2}-\gamma_{0}\|s\|^{(q+p) / p}+\left|\tanh \left(\operatorname{Fal}\left(e, k_{3}, c\right)\right)\right||s| \\
& \leq-\beta_{0}\|s\|^{2}-\left(\gamma_{0}-\left|\tanh \left(\operatorname{Fal}\left(e, k_{3}, c\right)\right)\right| /\|s\|^{q / p}\right)\|s\|^{(q+p) / p} \\
& \leq-\beta_{0}\|s\|^{2}-\left(\gamma_{0}-\varsigma /\|s\|^{q / p}\right)\|s\|^{q+p / p} \\
& =-2 \beta_{0} V-2^{(q+p) / 2 p} \gamma^{\prime} V^{(q+p) / 2 p} .
\end{aligned}
$$

It can be confirmed that $\gamma_{0}>\varsigma$, which leads to $\dot{V}<0$. Equation (37) proves equation (26) can be designed as the FNTSM, which converge in finite time. 


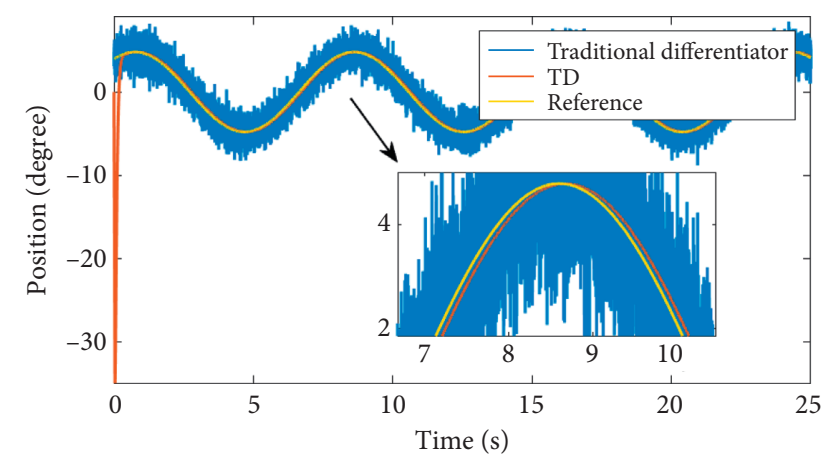

Figure 6: Differentiator with random noise.

\section{Simulation Studies}

Noise is amplified when using the traditional differentiator with the simultaneous action of the differential operation. With this in view, we attempted to use TD (equation (4)) to reduce noise. Compared with the traditional differentiator, the TD exhibits an antinoise capability, as shown in Figure 6. These experimental results prove the effectiveness of the TD in reducing noise. Certainly, the phase delay occurs in the TD; hence, Taylor's formula-based TD is carried out to solve this problem. Tracking the differential of $y=6 \cdot \sin (0.8 \cdot t)$, it turns out that Taylor's formula-based TD remains low phase delay by comparing TD in Figure 7.

In this section, step response and sinusoidal signal tracking experiments are conducted in Matlab. The robustness of the proposed method is validated by the step response with random disturbances experiment, and tracking performance is tested by sinusoidal tracking experiment.

It can be learned from Figure 8 that NADRC can reach the reference position within $0.75 \mathrm{~s}$, while ADRC and PID use $0.86 \mathrm{~s}$ and $1.41 \mathrm{~s}$ to reach it. This experimental result shows that, by using FNTSM, NADRC can reach the target position in shorter time. To verify the robustness of the system, step simulation with rapidly changing disturbances is conducted. The simulation results with different control methods are depicted in Figure 8; the proposed NADRC has relatively small fluctuation around $0.11^{\circ}$, while ADRC and PID methods are around $0.13^{\circ}$ and $0.18^{\circ}$, respectively. This simulation shows that NADRC has better antidisturbance ability in working process. It is proved that SESO can improve the antidisturbance practically.

As for the dynamic performance analysis of ADRC, PID, and NADRC, sinusoidal tracking simulation is carried out (see Figure 9). It is shown that PID tracking accuracy is worse than ADRC, while the NADRC tracks the reference signal more accurately than the traditional ADRC.

With sinusoidal tracking error curve drawn in Figure 10, the maximum tracking error of NADRC, ADRC, and PID is about $0.034^{\circ}, 0.086^{\circ}$, and $0.282^{\circ}$, respectively. Compared with PID and ADRC, NADRC has a faster convergence speed. Based on the above results, it can be seen that ADRC tracking error is more than twice that of NADRC, which proves that the proposed NADRC scheme has a faster

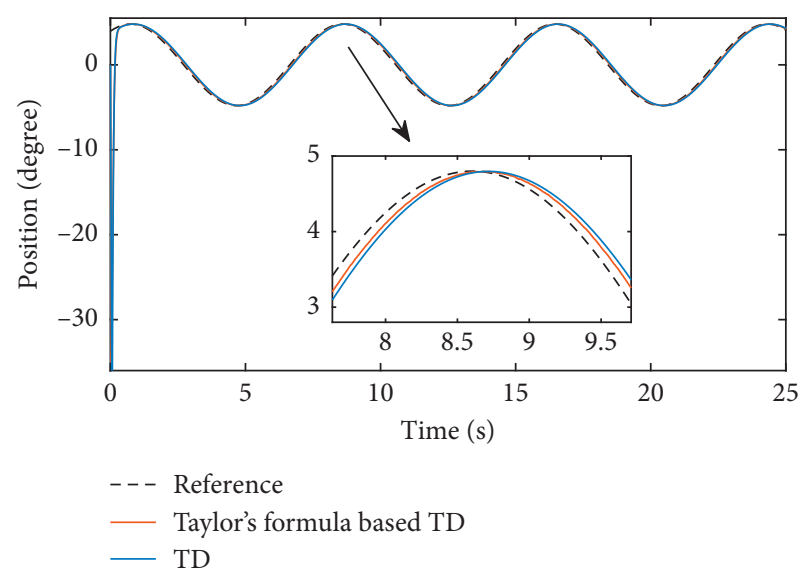

Figure 7: Tracking differentiator experiment.

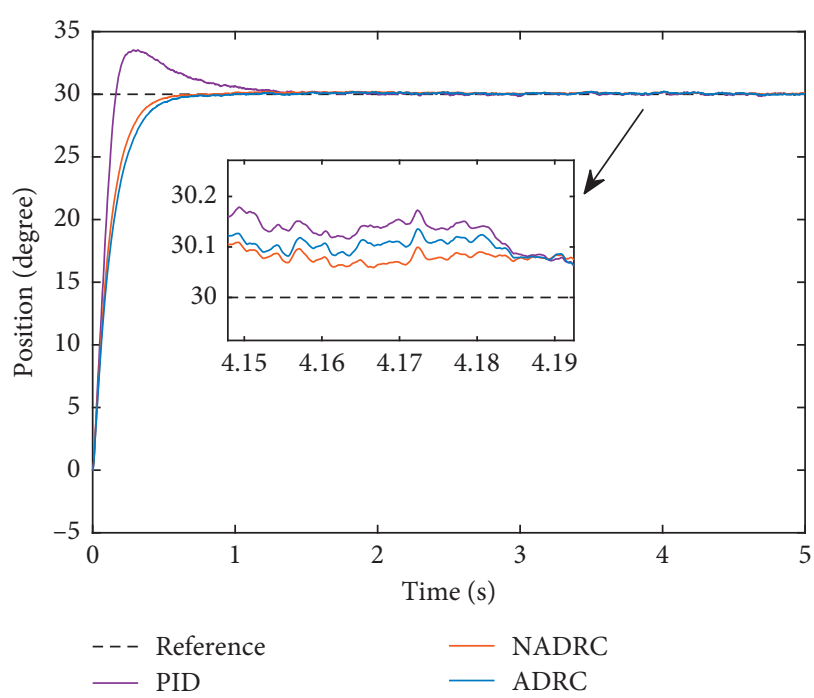

FIGURE 8: Step response simulation.

convergence speed and high tracking accuracy in this sinusoidal tracking simulation. The simulation result is shown in Table 1.

\section{Semiphysical Experiment}

To further verify the effectiveness of NADRC approach, a semiphysical experiment is conducted. The entire semiphysical experiment platform structure is shown in Figure 11. It can be seen that the platform is composed with control computer, sensor system, PA, PRG, AM, RIP, and the support frame. The disturbances are from frictional moment, load torque, and rotational inertia, which are simulated by RIP and MPB in this experiment. The motor parameters are listed in Table 2.

Maximum sampling frequency of $\mathrm{D} / \mathrm{A}$ transform is $100 \mathrm{kHz}$, with power amplifier transfer voltage from $28 \mathrm{~V}$ to $36 \mathrm{~V}$, which is $400 \mathrm{~Hz}$. The range of speed measurement is $0.03 \sim 100^{\circ} / \mathrm{s}$. Reduction ratio of precision gear box is 360: 1 . The rotational inertia of plate is $2.315 \cdot 10^{-4} \mathrm{~kg} \cdot \mathrm{m}^{2}$. The maximum magnetic power of brake is $108.7 \mathrm{kgf} \cdot \mathrm{m}$. The 


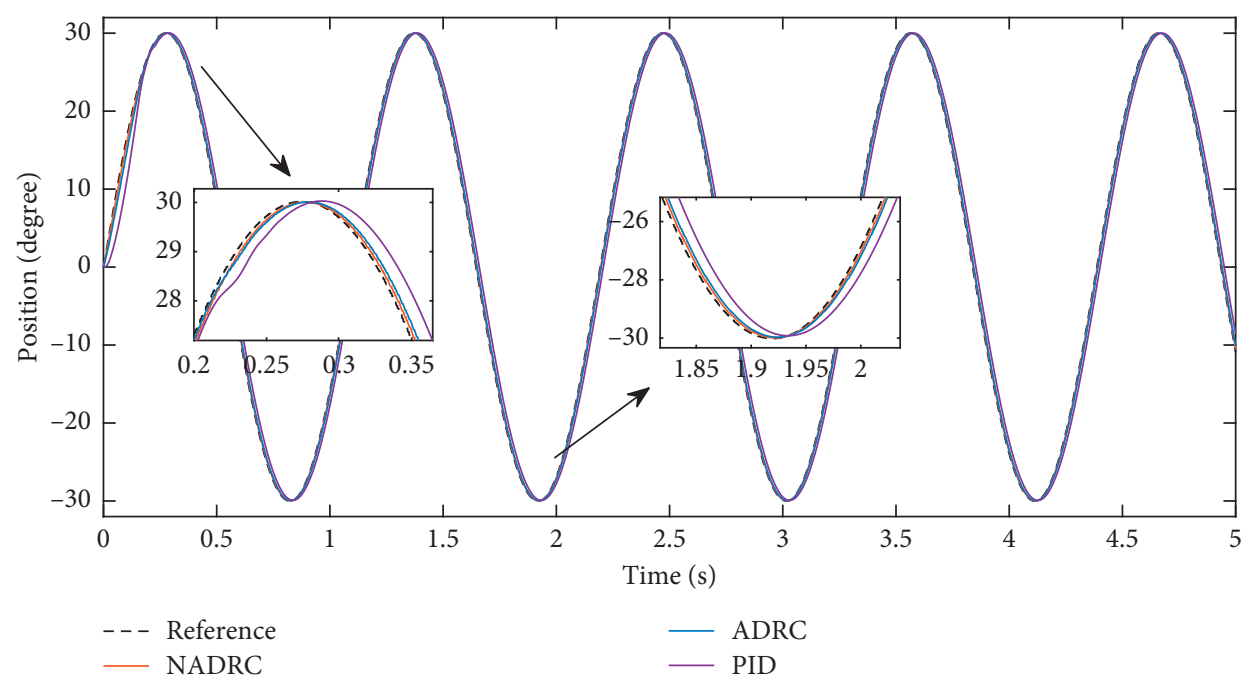

FIGURE 9: Sinusoidal tracking.

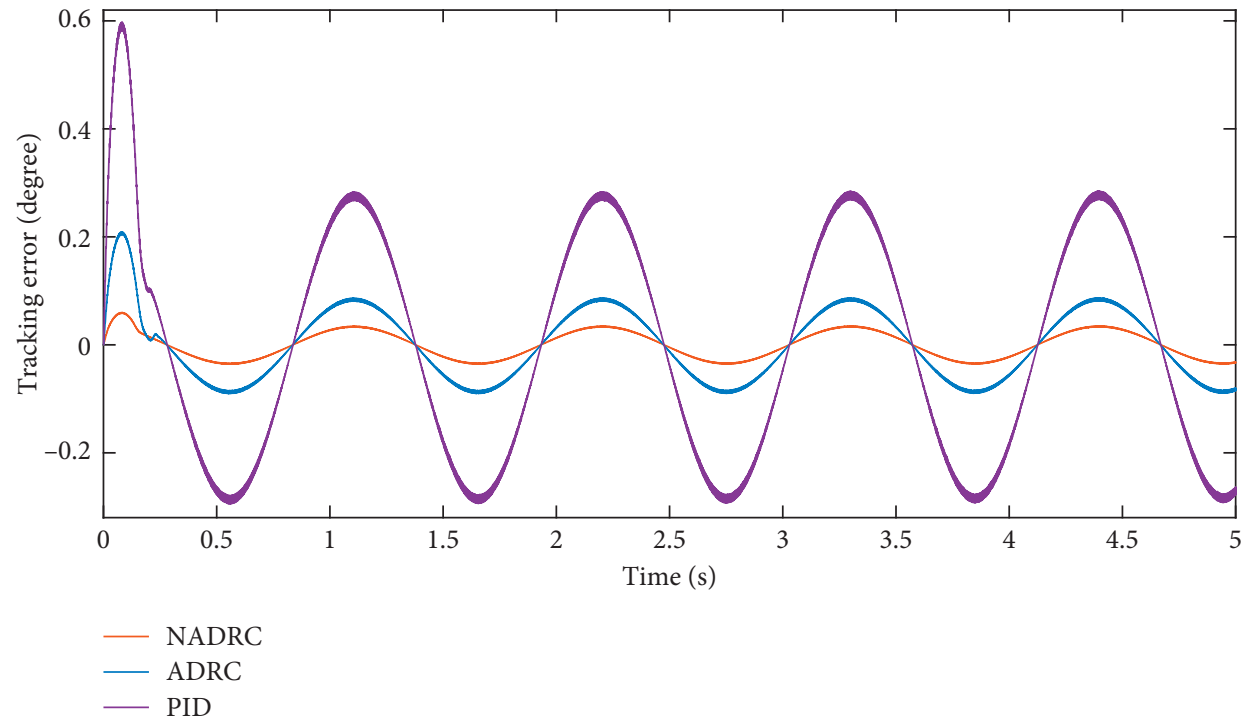

FIGURE 10: Sinusoidal tracking error.

TABLE 1: Parameters in PMSM.

\begin{tabular}{lccc}
\hline Control strategy & $\begin{array}{c}\text { Step simulation } \\
\text { Adjustment time (s) }\end{array}$ & $\begin{array}{r}\text { Sinusoidal tracking } \\
\text { Maximum error }\left({ }^{\circ}\right)\end{array}$ \\
\hline PID & 1.41 & Maximum error $\left(^{\circ}\right)$ & 0.282 \\
ADRC & 0.86 & 0.13 & 0.086 \\
NADRC & 0.75 & 0.11 & 0.034 \\
\hline
\end{tabular}

rated torque is $13.9 \mathrm{~N} \cdot \mathrm{m}(25 \mathrm{C}), 13.1 \mathrm{~N} \cdot \mathrm{m}(40)$, the maximum torque is $35.3 \mathrm{~N} . \mathrm{M}(25)$, the rated power is $5.4 \mathrm{~kW}$, the maximum voltage is $250 \mathrm{~V}$, the rated current is $19.8 \mathrm{~A}$, the maximum current is $40 \mathrm{~A}$, and the rated speed is $5000 \mathrm{rpm}$.

To verify the dynamic performance of the proposed NADRC scheme, a tracking experiment is conducted on the platform. The trajectory is a sinusoidal signal with a period of $3.768 \mathrm{~s}$ and amplitude of $30^{\circ}$. The experimental results of position, speed, and acceleration are shown in Figure 12. It can be seen from Figure 12 that the position tracking curve is the smoothest, and acceleration curve has relatively large fluctuation.

To further analyze the control accuracy, position tracking curve is partially enlarged in Figure 13 and the tracking error is drawn in Figure 14. It can be seen that the maximum position tracking error is hover around $0.6^{\circ}$. As is 

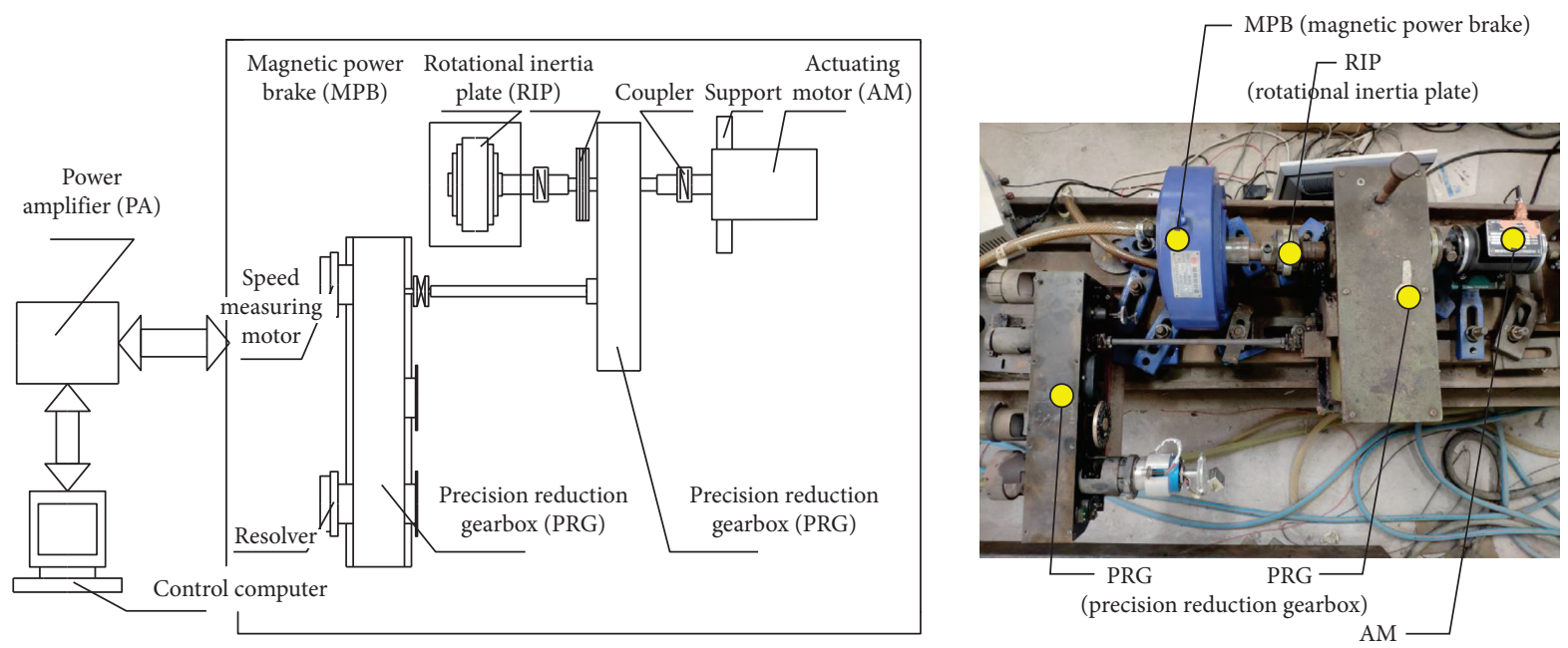

Figure 11: Semiphysical platform structure.

(actuating motor)

TABle 2: Parameters in PMSM.

\begin{tabular}{lc}
\hline Parameter & Value \\
\hline Load moment of inertia $(J)$ & $5.556 \times 10^{-3} \mathrm{~kg} \times \mathrm{m}^{2}$ \\
Friction coefficient $(B)$ & $1.43 \times 10^{-4}\left(\mathrm{~N} \times \mathrm{m}^{2} /\left(\mathrm{rad}^{-1}\right)\right.$ \\
Load disturbing moment $\left(T_{L}\right)$ & $9.32 \times 10^{3} \mathrm{~kg} \times \mathrm{m}^{2}$ \\
Motor torque factor $\left(K_{t}\right)$ & $0.175(\mathrm{~N} \times \mathrm{m}) / \mathrm{A}$ \\
Reduction ratio $(i)$ & 1039 \\
Stator inductance $\left(L_{d}=L_{q}\right)$ & $21.24 \mathrm{mH}$ \\
Pole pairs $(p)$ & 3 \\
Motor magnetic flux $\left(\psi_{f}\right)$ & $0.65 \mathrm{~Wb}$ \\
\hline
\end{tabular}

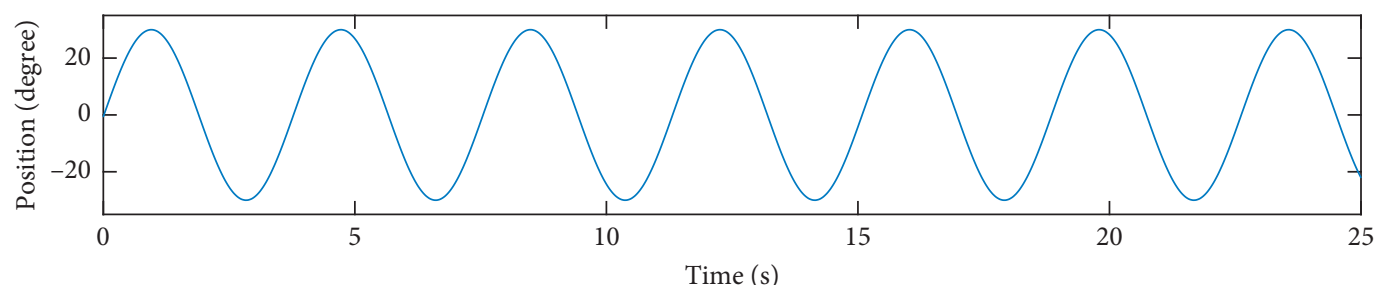

(a)

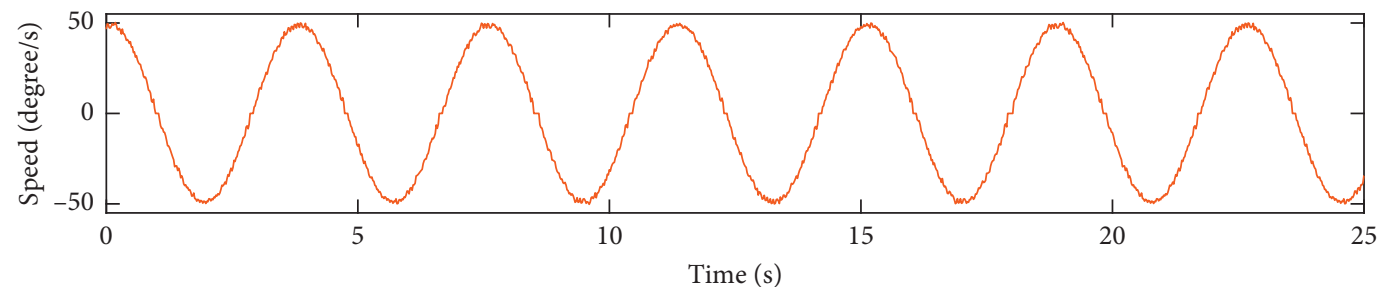

(b)

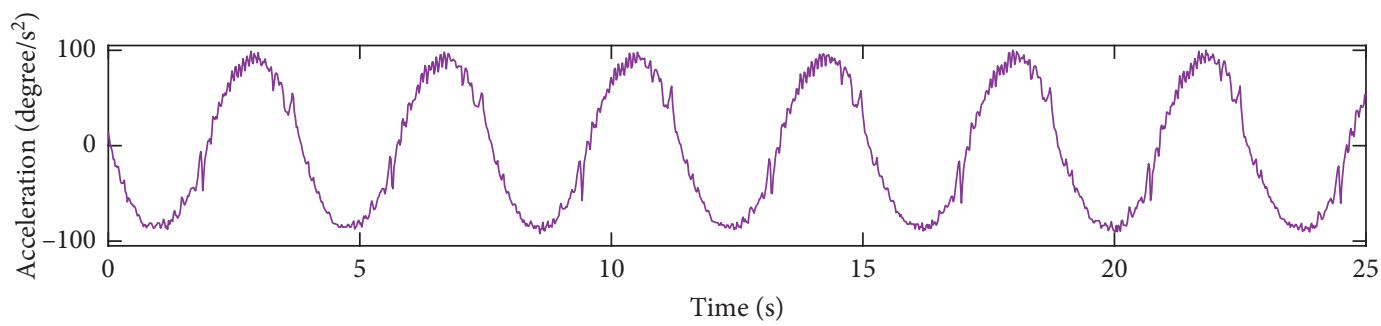

(c)

FIGURE 12: Sinusoidal tracking curves. 


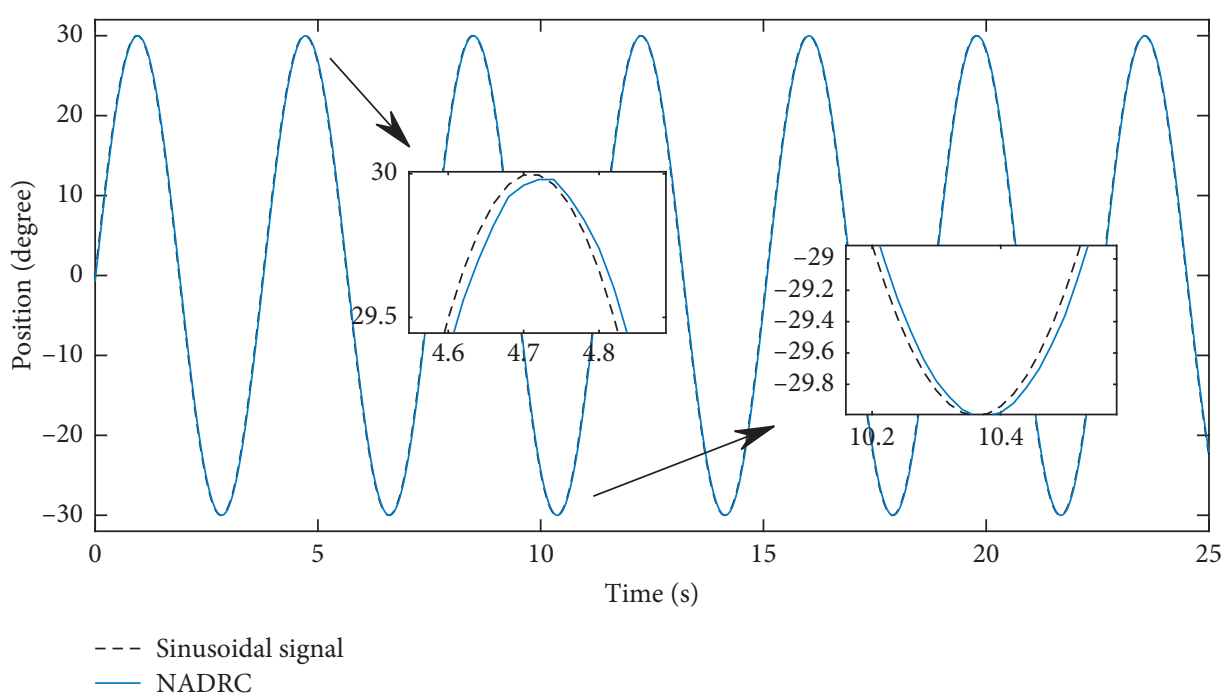

FIgURe 13: Position tracking curve.

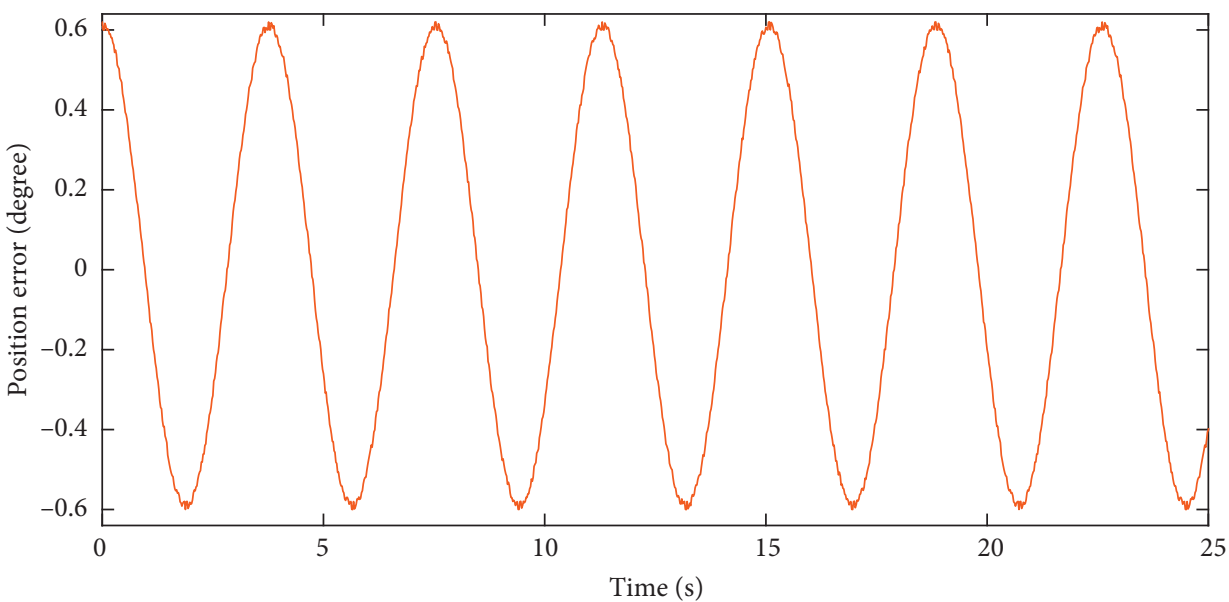

Figure 14: Position tracking error curve.

anticipated, the tracking error of the sinusoidal signal by NADRC meets the dynamic error index $0.2^{\circ}$, which proves its feasibility in practical applications.

\section{Conclusion}

In this paper, the position and speed control loop is innovated as a parallel structure with the proposed NADRC scheme. Both static and dynamic performances are successfully verified through step response simulation and sinusoidal signal tracking experiments. The step simulations are carried out with rapidly changing random disturbances for comparing PID, ADRC, and NADRC methods. Results show that NADRC can achieve target position quickly with better antidisturbance performance. Sinusoidal simulation results show Taylor's formula-based TD and SESO can reduce phase delay and acquire precise tracking performance. The position tracking in semiphysical experiment can meet the dynamic error index designed as $0.8^{\circ}$. Based on the above experiments and analysis, the proposed control method can be employed in this rocket launcher servo system, possibly employed in other practical applications in the future.

It is interesting that finite-time convergence is in conflict with chattering suppression problem. The super-twisting method has fast convergence speed, but it may cause a larger chattering problem [36]. In our future work, we try to combine it with low switching gain method and Kalman filter to address it.

\section{Data Availability}

The data used to support the findings of this study are available from the corresponding author upon request.

\section{Conflicts of Interest}

The authors declare no conflicts of interest.

\section{Acknowledgments}

This research was funded by the National Natural Science Foundation of China under Grant no. 51805264. 


\section{References}

[1] L. Zhao, Y. Xia, Y. Yang, and Z. Liu, "Multicontroller positioning strategy for a pneumatic servo system via pressure feedback," IEEE Transactions on Industrial Electronics, vol. 64, no. 6, pp. 4800-4809, 2017.

[2] T. Yang, N. Sun, H. Chen, and Y. Fang, "Neural network-based adaptive antiswing control of an underactuated ship-mounted crane with roll motions and input dead zones," IEEE Transactions on Neural Networks, vol. 31, no. 3, pp. 901-914, 2020.

[3] L. Wang, Q. Wu, J. Liu, S. Li, and R. R. Negenborn, "Ship motion control based on ambps-pid algorithm," IEEE Access, vol. 7, pp. 183656-183671, 2019.

[4] Y.-Y. He and X. Liu, "The accuracy control of target position servo system of rocket launcher," Computer Simulation, vol. 33, no. 9, p. 27, 2016.

[5] H. Katayama and H. Aoki, "Straight-line trajectory tracking control for sampled-data underactuated ships," IEEE Transactions on Control Systems Technology, vol. 22, no. 4, pp. 1638-1645, 2014

[6] D. F. Shi, Y. L. Hou, X. H. Gu, and R. M. Hou, "Improved finite control set optimal control for PMSM in rocket launcher servo system," Shock and Vibration, vol. 2020, no. 1, 11 pages, Article ID 3651298, 2020.

[7] J. Zhang, Y. Liu, F. Zhang, S. Gao, and C. Han, "Digital sliding mode control via a novel reaching law and application in shipborne electro-optical systems," IEEE Access, vol. 99, pp. 139870-139884, 2019.

[8] F.-B. Ge, X.-W. Sun, and D.-H. Wang, "Application of shipborne rocket in landing operations," Ship Electronic Engineering, vol. 33, no. 5, pp. 36-38, 2013.

[9] J. Du, X. Hu, and Y. Sun, “Adaptive robust nonlinear control design for course tracking of ships subject to external disturbances and input saturation," Systems Man and Cybernetics, vol. 50, no. 1, pp. 193-202, 2020.

[10] Y. Hui, R. Chi, B. Huang, and Z. Hou, "Extended state observer-based data-driven iterative learning control for permanent magnet linear motor with initial shifts and disturbances," IEEE Transactions on Systems, Man, and Cybernetics, vol. 51, pp. 1-11, 2019.

[11] X. Yu and M. Zhihong, "Fast terminal sliding-mode control design for nonlinear dynamical systems," IEEE Transactions on Circuits and Systems I-regular Papers, vol. 49, no. 2, pp. 261-264, 2002.

[12] L. Zhao and Y. Jia, "Neural network-based distributed adaptive attitude synchronization control of spacecraft formation under modified fast terminal sliding mode," Neurocomputing, vol. 171, pp. 230-241, 2016.

[13] J. Han, "From PID to active disturbance rejection control," IEEE Transactions on Industrial Electronics, vol. 56, no. 3, pp. 900-906, 2009.

[14] Li Sun, Y. Jin, and F. You, "Active disturbance rejection temperature control of open-cathode proton exchange membrane fuel cell," Applied Energy, vol. 261, Article ID 114381, 2020.

[15] W. R. Abdul-Adheem, I. K. Ibraheem, A. J. Humaidi, and A. T. Azar, "Model-free active input-output feedback linearization of a single-link flexible joint manipulator: an improved active disturbance rejection control approach," Measurement and Control, 2020.

[16] W. R. Abdul-Adheem, A. T. Azar, I. K. Ibraheem, and A. J. Humaidi, "Novel active disturbance rejection control based on nested linear extended state observers," Applied Sciences, vol. 10, no. 12, p. 4069, 2020.
[17] J. Feng, W. Wang, and Y. Chen, "An improved trackingdifferentiator filter based on Taylor's's formula," Optik-International Journal for Light and Electron Optics, vol. 158, pp. 1026-1033, 2018.

[18] J. Huang, P. Ma, G. Bao, F. Gao, and X. Shi, "Research on position servo system based on fractional-order extended state observer," IEEE Access, vol. 8, pp. 102748-102756, 2020.

[19] L. Zhao, C. Zheng, Y. Wang, and B. Liu, "A finite-time control for a pneumatic cylinder servo system based on a supertwisting extended state observer," IEEE Transactions on Systems, Man, and Cybernetics, vol. 51, pp. 1164-1173, 2019.

[20] D. Wang, J. Liu, S. Miao et al., "Rotor position estimation method for permanent magnet synchronous motor based on super-twisting sliding mode observer," in Proceedings of the Chinese Control Conference, IEEE, Wuhan, China, July 2018.

[21] T. Zhang, Z. Xu, J. Li, H. Zhang, and C. Gerada, "A thirdorder super-twisting extended state observer for dynamic performance enhancement of sensorless IPMSM drives," IEEE Transactions on Industrial Electronics, vol. 67, no. 7, pp. 5948-5958, 2020.

[22] Y. Han, Y. Cheng, and G. Xu, "Trajectory tracking control of AGV based on sliding mode control with the improved reaching law,” IEEE Access, vol. 7, pp. 20748-20755, 2019.

[23] Y.-W. Liang, S.-D. Xu, and D.-C. Liaw, "A study of T-S modelbased SMC scheme with application to robot control," IEEE Transactions on Industrial Electronics, vol. 55, no. 11, pp. 3964-3971, 2008.

[24] X. Zhang, L. Sun, K. Zhao, and L. Sun, "Nonlinear speed control for PMSM system using sliding-mode control and disturbance compensation techniques," IEEE Transactions on Power Electronics, vol. 28, no. 3, pp. 1358-1365, 2013.

[25] M. Cheema, J. Fletcher, M. Farshadnia, and M. Rahman, "Sliding mode based combined speed and direct thrust force control of linear permanent magnet synchronous motors with first-order plus integral sliding condition," IEEE Transactions on Power Electronics, vol. 34, no. 3, pp. 2526-2538, 2019.

[26] S. S. Xu, C. Chen, and Z. Wu, "Study of nonsingular fast terminal sliding-mode fault-tolerant control," IEEE Transactions on Industrial Electronics, vol. 62, no. 6, pp. 3906-3913, 2015.

[27] K. Shao, J. Zheng, K. Huang, H. Huang, Z. Man, M. Fu et al., "Finite-time control of a linear motor positioner using adaptive recursive terminal sliding mode," IEEE Transactions on Industrial Electronics, vol. 67, pp. 6659-6668, 2019.

[28] X. Liang, S. Li, and J. Fei, "Adaptive fuzzy global fast terminal sliding mode control for microgyroscope system," IEEE Access, vol. 4, pp. 9681-9688, 2016.

[29] M. Van, "An enhanced robust fault tolerant control based on an adaptive fuzzy PID-nonsingular fast terminal sliding mode control for uncertain nonlinear systems," IEEE-ASME Transactions on Mechatronics, vol. 23, no. 3, pp. 1362-1371, 2018.

[30] X. Zhao and D. Fu, “Adaptive neural network nonsingular fast terminal sliding mode control for permanent magnet linear synchronous motor," IEEE Access, vol. 7, pp. 180361-180372, 2019.

[31] J. Baek, W. Kwon, and C. Kang, "A new widely and stably adaptive sliding-mode control with nonsingular terminal sliding variable for robot manipulators," IEEE Access, vol. 8, pp. 43443-43454, 2020.

[32] C. Chen, Z. Du, L. He, J. Q. Wang, D. M. Wu, and W. Dong, "Active disturbance rejection with fast terminal sliding mode control for a lower limb exoskeleton in swing phase," IEEE Access, vol. 7, pp. 72343-72357, 2019. 
[33] C. Liu, G. Luo, X. Duan, Z. Chen, Z. Zhang, and C. Qiu, "Adaptive LADRC-based disturbance rejection method for electromechanical servo system," IEEE Transactions on Industry Applications, vol. 56, no. 1, pp. 876-889, 2020.

[34] S. Li, S. Ding, H. Du, and C. Qian, Theory and Application of Non-smooth Control, Science Press, Beijing, China, 2013.

[35] H. Yu, Z. Kang, and C. Yao, "Time-varying parameter secondorder extended state observer based on hyperbolic tangent function," Control Theory \& Applications, vol. 33, no. 4, pp. 530-534, 2016.

[36] V. Utkin, "Discussion aspects of high-order sliding mode control," IEEE Transactions on Automatic Control, vol. 61, no. 3, pp. 829-833, 2016. 